\title{
Primary Frequency Control Ancillary Service in Distribution Network by Coordinated Scheduling of Wind Power and Demand Response
}

\author{
Meysam Khojasteh, Pedro Faria, Zita Vale \\ Polytechnic Porto \\ Porto, Portugal \\ meysa@isep.ipp.pt, pnf@isep.ipp.pt, zav@isep.ipp.pt
}

\begin{abstract}
Frequency is the main parameter that reflects the stability of power system, and mismatches between generation and consumption. Increasing the penetration level of renewable energy resource in distribution network, and their noticeable participation level to provide the required electricity lead to a new challenge for the distribution system operators (DSO). The variable nature of renewable resources is inevitable, and this uncertainty can lead to instability of power systems. Therefore, DSO shall use more flexible and schedulable resource to maintain the security of network in the acceptable level. In this work, Demand response (DR) program is proposed as the backup resource for compensating the wind power uncertainty in primary frequency control (PFC). The proposed model specifies the required capacity of $D R$ resource to maintain the frequency of grid in the allowable region, based on the uncertainty of wind generation. The performance of proposed model will be investigated by a case study.
\end{abstract}

Index Terms-- Demand response, distribution network, primary frequency control, wind power, uncertainty.

\section{INTRODUCTION}

Power system security includes the proper scheduling of generating resource to continue the reliable operation when a component fails or unpredicted fluctuations happen in generation or consumption. The frequency is the main parameter that reflects the stability of power system, and any mismatches between generation and consumption result frequency deviation from the nominal value. In traditional power systems, the governors of large-scale generators perform the frequency control. Emerging the smart grids and micro-grids change the frequency control paradigm by proposing the regional frequency control strategy in the distribution network. Increasing the penetration level of renewable energy resource in distribution network, and their noticeable participation level to provide the required electricity of final consumers lead to a new challenge for the distribution system operators (DSO). It shall be noted that variable nature of renewable resources is not ignorable. Moreover, all forecasting methodologies include the

This work received funding from FEDER Funds through COMPETE program and from National Funds through FCT under the project UID/EEA/00760/2019. prediction error. Therefore, the fluctuations of renewable energy resources can threaten the security of power system, and lead to the instability.

The frequency control in distribution network has been investigated in different technical references. In [1], a coordinated model for integration of demand response and droop controlled based resources is proposed. The droop control strategy is the most common technique to control the generation of synchronous generator based on the grid frequency excursion. In this strategy, the governor valve and consequently the input mechanical power is adjusted based on the frequency of grid. In some renewable energy resources such as energy storage, there is no governor valve or input mechanical power. In other words, the droop controller shall be designed according to the characteristics of the generating resource, which is neglected in the proposed model of [1]. The proposed model of [2] uses the battery energy storages as the backup resource of wind power for participation in frequency regulation service. However, the dynamic behavior of these renewable resources is ignored in the model. In [3], the state of charge constraints of energy storages is considered in the designing of frequency controller. The recent advances in designing smart controlling devices, and variety benefits of DR programs such as fast response, low cost, flexibility, and availability increase the attention of researchers to these resources. In [4], DR is proposed for frequency regulation services. It shall be noted that the technical constraints of DR are not considered in this model. The coordination of battery energy storage, electric water heaters, and DR programs for participating in frequency ancillary service is investigated in [5]. The performance of proposed model can be improved via modeling the dynamic behaviors of DR and water heating resources. In [6], domestic refrigerators are proposed as a controllable load to provide the frequency regulation service. However, the refrigerator loads are not frequency-sensitive resource, and in frequency regulation service, they only can be used as interruptible loads. In this case, the dependency of desirable performance of appliances to the interruption duration shall be considered. In [7], DR programs are 
proposed to improve the maneuverability and stability of grid. However, increasing DR programs' participation level in the frequency ancillary service could decrease the inertia of power system and its resistance against contingencies. Authors in [8] provide a stochastic model for scheduling decentralized demand response resources that ensures insensibility to variation of consumers' satisfaction parameters (e.g. the temperature of refrigerator or air conditioner). The experimental results of using DR as a frequency-controlled reserve on appliances with programmable thermostats are presented in [9], which show the potential of refrigerators to provide frequency reserves approximately equal to their average consumption. Optimal parameters of controller for commitment of DR in frequency regulation service are presented in [10].

It shall be noted that when a contingency happens in power system, two critical activities shall be performed:

- Returning the frequency to the allowable range, which is performed by Primary Frequency Control (PFC),

- Returning the frequency to the nominal value, which is performed by Secondary Frequency Control (SFC).

This paper presents a model for scheduling of wind generating units and DR resources in PFC. The frequency response of wind units depends on the characteristics of wind turbine and generator, which shall be considered in PFC. Moreover, the control of mechanical power in wind units is a little different from the synchronous generators. The input mechanical power of wind generator can be adjusted by the pitch angle of blades and horizontal axis of wind turbine.

In this work, the droop control strategy is used to adjust the blades pitch angle based on the frequency excursion of grid. Moreover, the frequency-sensitive load model is suggested as a backup resource to cover the limitation of wind units for participation in PFC. As mentioned before, the main objective of DSO in PFC is maintaining the frequency of network within the acceptable range. Therefore, the proposed objective function is formulated based on the minimum frequency excursion. The uncertainty of wind speed is modeled by the various scenarios, and the stochastic programming framework is suggested to specify the optimal scheduling of wind units and DR programs in PFC. The proposed scenario-based stochastic problem determines the required capacity of DR resource to maintain the frequency of grid in the allowable region, based on the uncertainty of wind generation. The main contributions of this work can be summarized as follows:

- Modeling wind turbine and generator in PFC,

- Proposing the droop control scheme to adjust the pitch angle of blades based on the frequency excursion of grid.

The rest of paper is organized as follow: In subsection II, the dynamic model for scheduling of wind power, DR resources, and the proposed objective function are presented. The numerical simulation and discussions are presented in section III. Finally, conclusions and remarks are presented in section IV.

\section{SCHEDULING OF WIND GENERATING UNITS AND DR FOR PARTICIPICATION IN PFC}

\section{A. Wind Generating Units}

The electromechanical response of power systems can be modeled as follow:

$$
\frac{2 H_{s}}{\omega_{s}} \frac{d \Delta \omega_{N}}{d t}+D_{s} \Delta \omega=\Delta P_{M}-\Delta P_{E}
$$

Where, $P_{M}, P_{E}, \omega_{N}, \omega_{s}, D_{s}$, and $H_{s}$ are input mechanical power, electrical load, network angular frequency, reference frequency, damping and system inertia constants of power system, respectively.

Fig. 1 shows the different torques on the shaft axis of wind generating unit. Occurrence of the contingency can change the electrical torque $\left(T_{E}\right)$. The mechanical torque $\left(T_{M}\right)$ and the absorbed power depend on wind speed, weather condition, characteristics of blades. Evidently, the main parameter that can be adjusted by the operator (or controller) to control $T_{M}$ is the pitch angle of blades. The turbine-generator torque $\left(T_{T G}\right)$ is determined by the shaft stiffness and angular displacement between shaft ends.

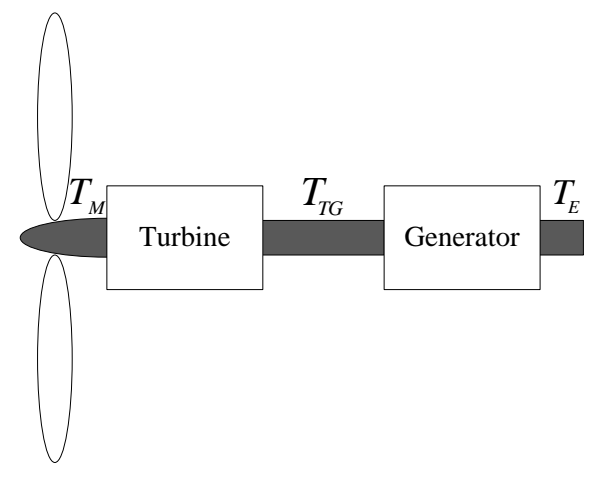

Figure 1. Wind generating unit.

The electromechanical response of wind resource can be formulated as follows [11]:

$$
\begin{gathered}
\frac{d \omega_{T}}{d t}=\frac{\Delta T_{M}-\Delta T_{T G}}{2 H_{T}} \\
\frac{d \omega_{G}}{d t}=\frac{\Delta T_{T G}-\Delta T_{E}}{2 H_{G}} \\
\Delta T_{T G}=S \Delta \theta \\
\frac{d \theta}{d t}=\omega_{N} \times\left(\omega_{T}-\omega_{G}\right)
\end{gathered}
$$

where, $\omega_{T}$ and $\omega_{G}$ are frequencies of turbine and generator, $H_{T}$ and $H_{G}$ are inertia constants of turbine and generator, $S$ and $\theta$ are shaft stiffness and angular displacement between shaft ends, respectively. The electromechanical response of turbine and generator are represented by (2) and (3), respectively. Moreover, the turbine-generator torque and variation of angular displacement between shaft ends are calculated by (4) and (5), respectively. The extracted mechanical power by wind turbine is calculated as follows:

$$
P_{M}=0.5 \rho A v^{3} F_{w}(\alpha, \beta)
$$




$$
\begin{gathered}
F_{w}(\alpha, \beta)=0.73\left(\frac{151}{\alpha_{i}}-0.58 \beta-0.002 \beta^{2.14}-13.2\right) e^{-18.4 / \alpha_{i}} \\
\alpha_{i}=\left(\frac{1}{\alpha-0.02 \beta}-\frac{0.003}{\beta^{3}+1}\right)^{-1}
\end{gathered}
$$

where, $\rho, A, v, \alpha$, and $\beta$ are the air density $\left(\mathrm{kg} / \mathrm{m}^{3}\right)$, rotor sweep area $\left(\mathrm{m}^{2}\right)$, wind speed $(\mathrm{m} / \mathrm{s})$, tip speed ratio, blade pitch angle (deg), respectively. The main operational constraints of wind units are capacity (9), mechanical ramp-up (10) and ramp-down (11) rates, and blade pitch angle (12), which are formulated as follows:

$$
\begin{gathered}
P_{M}^{\min } \leq P_{M}(t) \leq P_{M}^{\max } \\
P_{M}(t)-P_{M}(t-1) \leq R^{U} \\
P_{M}(t-1)-P_{M}(t) \leq R^{D} \\
\beta^{\min } \leq \beta \leq \beta^{\max }
\end{gathered}
$$

To control the mechanical power of wind resource, the droop control methodology is used in this work. The typical formulation of active power droop controller can be represented as follow:

$$
m_{w}\left(\Delta P_{E}-\Delta P_{M}\right)=\left(\omega_{N}-\omega_{s}\right)
$$

where $m_{w}$ is the damping factor of droop controller. Evidently, by increasing the frequency of grid, the mechanical power shall be decreased, and vice versa. According to (6), the formulation of droop controller can be rewritten as follow:

$$
F_{w}\left(\alpha, \beta_{2}\right)=\frac{2}{\rho A v^{3}}\left(\Delta P_{E}-\frac{1}{m_{w}}\left(\omega_{N}-\omega_{s}\right)\right)+F_{w}\left(\alpha, \beta_{1}\right)
$$

In this work, it is supposed that within the short period of PFC, the wind speed is fixed and according to (14) the absorbed mechanical power can be adjusted by angle pitch of blades $(\beta)$. The presented function in (14) is nonlinear and to solve it, the numerical analysis method such as NewtonRaphson can be used.

\section{B. Frequency-sensitive Load}

DR is another important resource that can be used to control of frequency of grid and enhance the stability of power system. Usually, appliances that have the capability of store thermal energy for short interruption period such as freezer, refrigerator, heater have the capability to participate in PFC. It shall be noted that the duration of interruption or load reduction shall be low enough to prevent the consumers' inconvenience. The consumption of end-users can be represented as follow:

$$
D=D_{F}+D_{E}
$$

where, $D_{F}$ and $D_{E}$ are fixed and elastic terms of consumption, respectively. In over-frequency/under-frequency conditions, end-users can participate in PFC by increasing/decreasing the consumption, as follow:

$$
\Delta \omega=\omega_{s}-\omega_{N}
$$

$$
D_{E}=\left\{\begin{array}{cc}
-m_{D R} D_{E}^{\max } & \Delta \omega \geq \Delta \omega_{\max } \\
-m_{D R} D_{E}^{\max } \Delta \omega & -\Delta \omega_{\max } \leq \Delta \omega \leq \Delta \omega_{\max } \\
m_{D R} D_{E}^{\max } & \Delta \omega \leq-\Delta \omega_{\max }
\end{array}\right.
$$

where, $m_{D R}$ is the frequency sensitivity factor, and it is determined based on the market share of consumption in PFC service (which is determined by the operator). Moreover, $D_{E}^{\max }$ is the maximum capacity of load in PFC, and it is specified based on the type and characteristics of load.

\section{Wind Uncertainty}

The uncertainty of wind speed is the main challenge of wind resource that limits its participation level in PFC. In this work, the scenario generation methodology is used to model the uncertainty of wind speed. The stochastic behavior of wind speed is approximated by the normal distribution function, and seven scenarios are considered for each time interval. The scenario vector of $v$, which is represented by $V$, is calculated as follow:

$$
V(t)=\left\{\begin{array}{l}
\mu(t)-3 \sigma(t), \mu(t)-2 \sigma(t), \mu(t)-\sigma(t), \mu(t), \\
\mu(t)+\sigma(t), \mu(t)+2 \sigma(t), \mu(t)+3 \sigma(t)
\end{array}\right\}
$$

where, $\mu$ and $\sigma$ are the average value and standard deviation of wind speed, respectively. Moreover, The probability of scenarios $(\gamma)$ is calculated by cumulative distribution function.

\section{Operational Cost}

In this work, the total operational cost for PFC includes the cost of wind resource and DR for participation in PFC. To calculate the cost of wind resource, it is supposed that turbine and generator have no loss $\left(P_{M}=P_{G}\right)$, and the operator pays the operational cost to these resources. Therefore, the cost function of wind resource is formulated as follow:

$$
C_{w}=a P_{G}+b
$$

where, $a$ and $b$ are coefficients of wind resource's cost function. The cost function of DR programs includes the capacity (that is paid for $D_{E}^{\max }$ ) and actual (that is paid for $D_{E}$ ) costs, as follow:

$$
C_{D R}=D_{E}^{\max } \times \pi_{c a p}+D_{E} \times \pi_{a c t}
$$

where $\pi_{\text {cap }}$ and $\pi_{\text {act }}$ are the capacity and actual prices. The total operational $\operatorname{cost}(C)$ is calculated as follow:

$$
C=C_{w}+C_{D R}
$$

\section{E. Objective Function}

As mentioned before, the main objective of operator in PFC is minimizing the frequency excursion. In this work, the operational cost is considered as a constraint in the optimization problem, and the available resources are scheduled in a way that the total operational cost be less than the fixed value, which is determined by the decision-maker. The objective function is represented by (22), where, I, $T$, and 
$\Psi$ are set of wind scenarios, planning period, and cost cap, respectively.

$$
\begin{array}{r}
O F: \min \sum_{t \in T} \sum_{\eta \in \mathrm{I}}\left|\Delta \omega_{\eta}(\mathrm{t})\right| \gamma_{\eta} \\
\sum_{t \in T} \sum_{\eta \in \mathrm{I}} C_{\eta}(t) \leq \Psi
\end{array}
$$

$$
\text { Constraints : (9)-(12) }
$$

\section{SimUlATION AND NUMERICAL RESUlTS}

To evaluate the performance of the proposed model, it is simulated on a test system by four case studies. Table I presents the data of wind resource [13].

TABLE I. DATA OF WIND RESOURCE

\begin{tabular}{|c|c|}
\hline Item & Value \\
\hline Tip speed ration & 4 \\
\hline Frequency of grid & 50 \\
\hline Shaft stiffness & 0.3 p.u./rad(e) \\
\hline Inertia of wind turbine & 1.25 \\
\hline Inertia of wind generator & 1.25 \\
\hline Inertia of system & 5 \\
\hline A (m2) & 4418 \\
\hline Air density & 1.225 \\
\hline
\end{tabular}

Case I: In this case, it is supposed that a loss of generation $1 \mathrm{MW}$ is happened within $100 \mathrm{msec}$ in system. The wind speed is $1 \mathrm{~m} / \mathrm{s}$ and its uncertainty is neglected. Fig. 2 shows the frequency response of wind resources to the contingency.

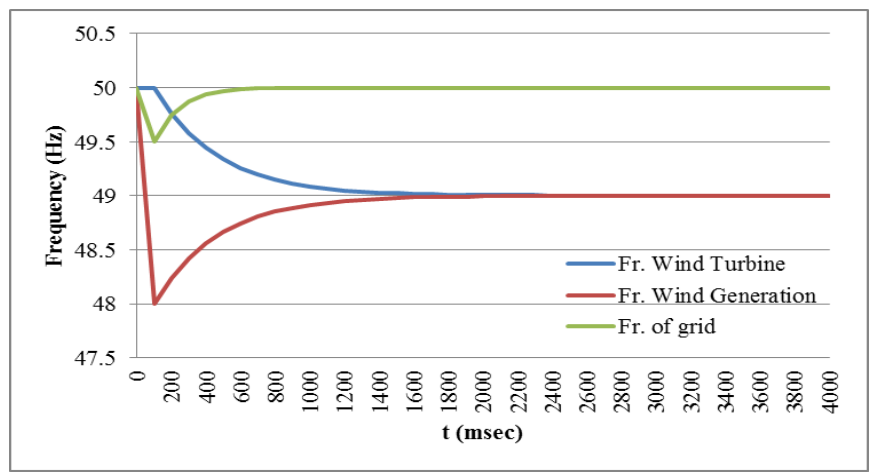

Figure 2. Frequency response of wind generating unit in Case I.

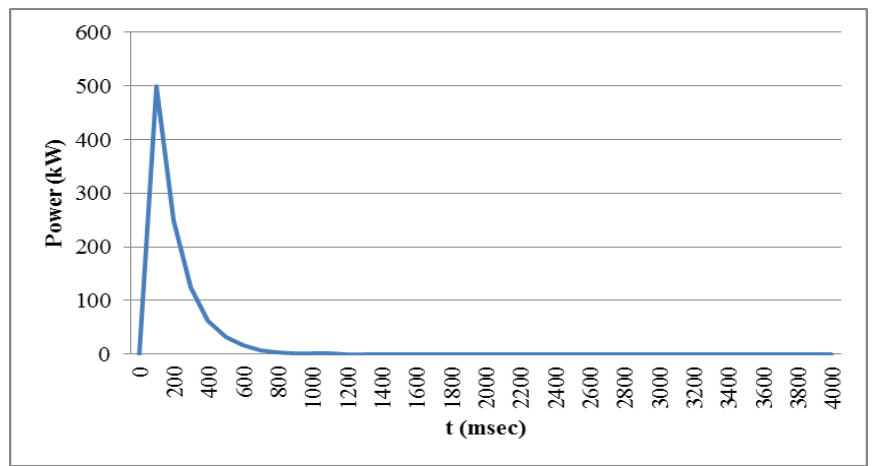

Figure 3. Injected mechanical power by wind generating unit in Case I.

The inertia of power system is higher than the windgenerating unit. Therefore, the frequency reduction in turbine and generator is higher than the system. The injected mechanical power for $m_{w}=1$, is represented in Fig. 3 . According to Fig. 2, after $700 \mathrm{msec}$, the frequency of grid reaches to its nominal value. However, there is a difference between frequencies of turbine and generator. After $700 \mathrm{msec}$, the mechanical power could not be injected into system (to prevent over frequency in the grid). Therefore, the wind power generating system tries to adjust frequencies of turbine and generator by changing $\theta$. To return the frequency of wind resource to $50 \mathrm{~Hz}$, the blade pitch angle can be readjusted, and over generation shall absorbed by a load (e.g. energy storage).

Case II: In case II, it is supposed that that the ramp rate of wind resource is $1 \mathrm{MW} / \mathrm{sec}$. The impact on ramp rate on frequency response of wind resource and absorbed mechanical power are represented in Fig. 4 and 5, respectively. According to Fig.4, considering the ramp rate would increase the restoration time of frequency from $700 \mathrm{msec}$ to $1200 \mathrm{msec}$. It is worthy to be noted that in these case studies, it is supposed that the controller starts to adjust the mechanical power after the contingency.

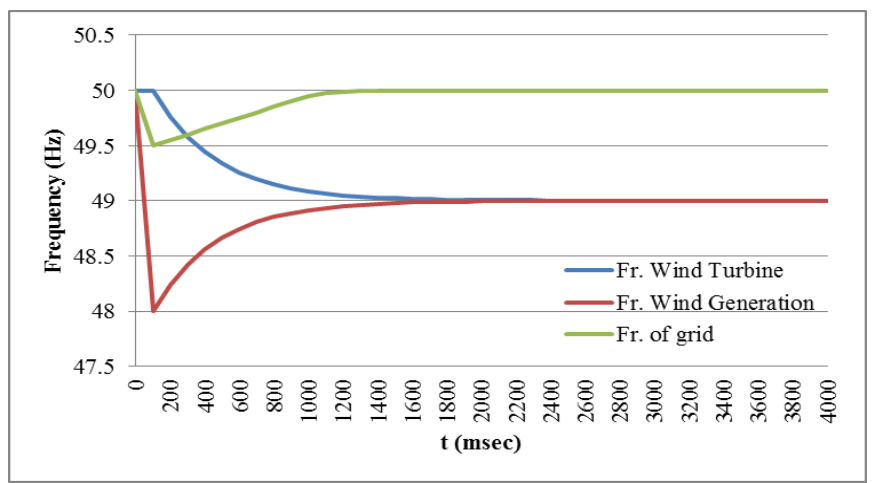

Figure 4. Frequency response of wind generating unit in Case II.

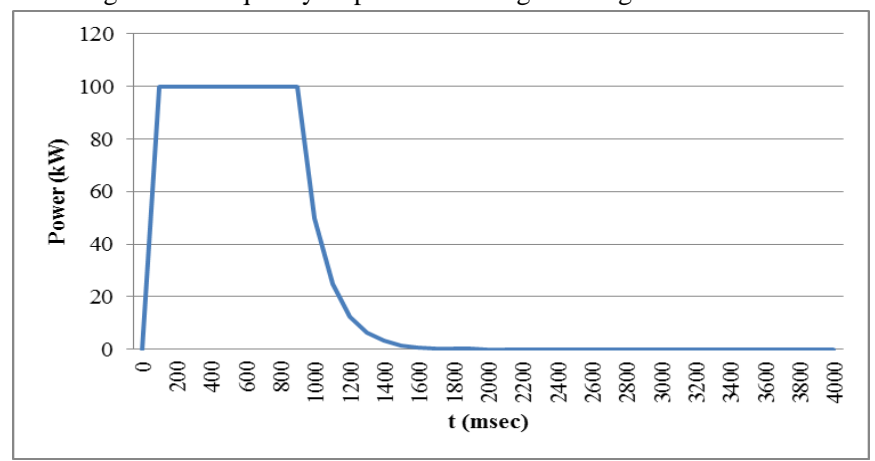

Figure 5. Injected mechanical power by wind generating unit in Case II.

Case III: In case III, DR is considered as the only resource, which can be used for the frequency regulation. Fig. 6 shows the sensitivity of grid frequency to $m_{D R}$. In this case, it is supposed that the maximum variation of $D_{E}$ in $100 \mathrm{msec}$ is $100 \mathrm{~kW}$.

Case IV: Finally, in the fourth case study, both DR (with $m_{D R}=2$ ) and wind resources (with ramp-rate constraint) are used for PFC. The uncertainty of wind speed is modeled by $\mu=1(\mathrm{~m} / \mathrm{s})$ and $\sigma=0.05(\mathrm{~m} / \mathrm{s})$. Moreover, the cost function coefficients of wind resource are $a=20 \mathrm{C} / \mathrm{kWh}$ and $b=0$. The capacity and calling price of DR resource are 2 and 
$10 \mathrm{C} / \mathrm{kWh}$. In this case study, cost cap is 1 Euro/second. Fig. 8 and 9 show the frequencies (grid, turbine, and generator), and the power (injected mechanical power and load reduction) in case IV, respectively.

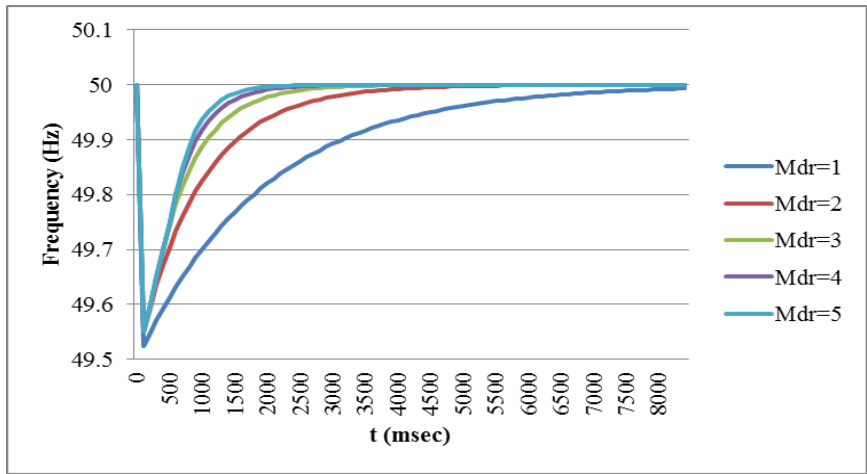

Figure 6. Frequency response of DR resource in Case III.

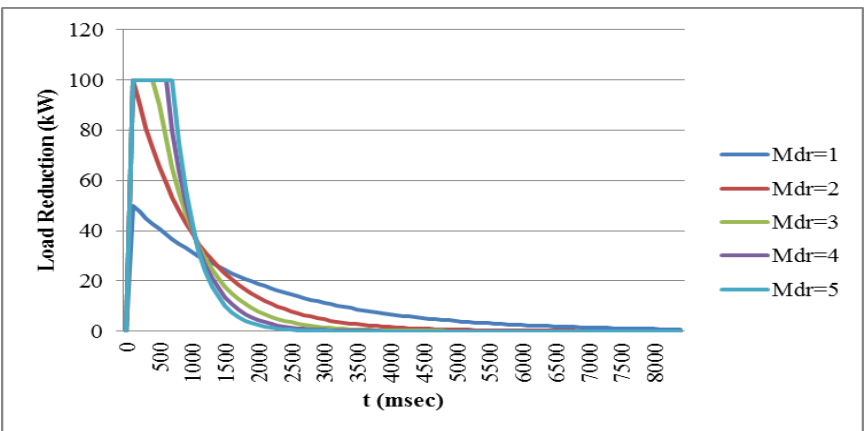

Figure 7. Load reduction of DR resource in Case III.

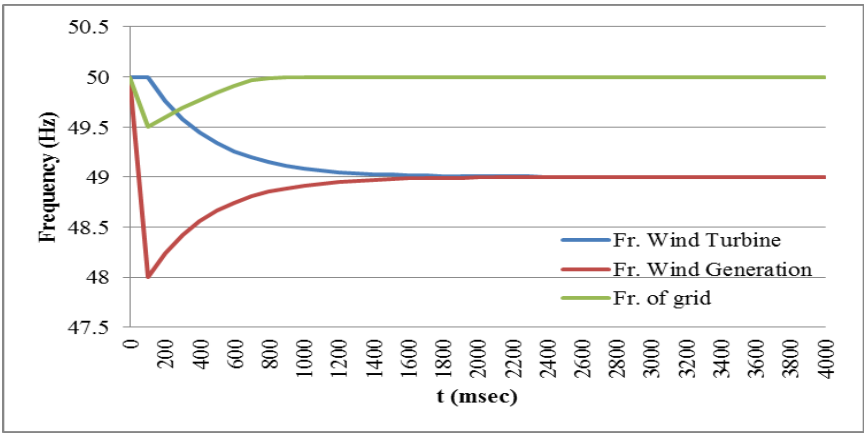

Figure 8. Frequency response of DR resource in Case IV.

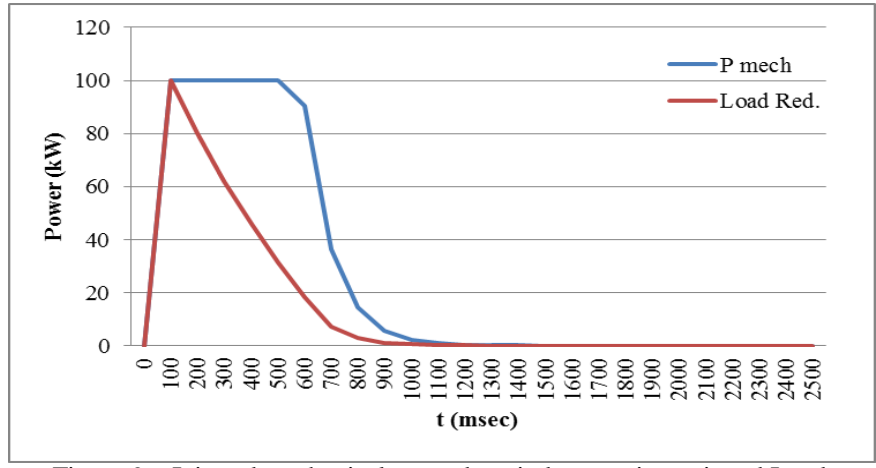

Figure 9. Injected mechanical power by wind generating unit and Load reduction of DR resource in Case IV.
Comparing Fig. 4 and 8 demonstrates that considering the DR programs could reduce the stabilization time of frequency from $1200 \mathrm{msec}$ to $620 \mathrm{msec}$. Moreover, Fig. 9 shows the DR resource could decrease the injected mechanical power by the wind resource. The total cost for duration of frequency stabilization (which is less than $1 \mathrm{sec}$ ) is $550 \mathrm{C}$. It shall be noted that the total operation cost in case II is $680 \mathrm{C}$, and the restoration time is higher than case IV.

\section{CONCLUSIONS}

In this paper, a coordinated model is proposed for scheduling of wind units and DR in PFC. The limitations of wind turbine and generator are considered in the proposed model. The simulation results show that considering DR could decrease the required time to return the frequency of grid to its nominal value after contingency. Moreover, the injected mechanical power by the wind resource can be decreased by DR, which hedges the risk of wind uncertainty. As a part of future work, the authors are going to develop the proposed model by adding other controllable energy resources.

\section{REFERENCES}

[1] Rezaei, N., \& Kalantar, M. (2015). Smart microgrid hierarchical frequency control ancillary service provision based on virtual inertia concept: An integrated demand response and droop controlled distributed generation framework. Energy Conversion and Management, 92, 287-301.

[2] He, G., Chen, Q., Kang, C., Xia, Q., \& Poolla, K. (2016). Cooperation of wind power and battery storage to provide frequency regulation in power markets. IEEE Transactions on Power Systems, 32(5), 35593568.

[3] Mercier, P., Cherkaoui, R., \& Oudalov, A. (2009). Optimizing a battery energy storage system for frequency control application in an isolated power system. IEEE Transactions on Power Systems, 24(3), 14691477.

[4] Pourmousavi, S. A., \& Nehrir, M. H. (2012). Real-time central demand response for primary frequency regulation in microgrids. IEEE Transactions on Smart Grid, 3(4), 1988-1996.

[5] Motalleb, M., Thornton, M., Reihani, E., \& Ghorbani, R. (2016). Providing frequency regulation reserve services using demand response scheduling. Energy Conversion and Management, 124, 439-452.

[6] Malik, A., \& Ravishankar, J. (2018). A hybrid control approach for regulating frequency through demand response. Applied Energy, 210, 1347-1362.

[7] Bao, Y. Q., Shen, C., Wang, Q., \& Zhang, J. L. (2019). Demand response based on Kalman-filtering for the frequency control. Journal of Electrical Engineering \& Technology, 14(3), 1087-1094.

[8] Benysek, G., Bojarski, J., Smolenski, R., Jarnut, M., \& Werminski, S. (2016). Application of stochastic decentralized active demand response (DADR) system for load frequency control. IEEE Transactions on Smart Grid, 9(2), 1055-1062.

[9] Douglass, P. J., Garcia-Valle, R., Nyeng, P., Østergaard, J., \& Togeby, M. (2013). Smart demand for frequency regulation: Experimental results. IEEE Transactions on smart grid, 4(3), 1713-1720.

[10] Bao, Y. Q., Li, Y., Wang, B., Hu, M., \& Chen, P. (2017). Demand response for frequency control of multi-area power system. Journal of Modern Power Systems and Clean Energy, 5(1), 20-29.

[11] Ackermann, T. (Ed.). (2005). Wind power in power systems. John Wiley \& Sons.

[12] Slootweg, J. G., De Haan, S. W. H., Polinder, H., \& Kling, W. L. (2003). General model for representing variable speed wind turbines in power system dynamics simulations. IEEE Transactions on power systems, 18(1), 144-151.

[13] Slootweg, J. G., Polinder, H., \& Kling, W. L. (2003). Representing wind turbine electrical generating systems in fundamental frequency simulations. IEEE Transactions on energy conversion, 18(4), 516-524. 